\title{
Jorge Amado y su Tienda de los milagros: una mirada desde la poética de la diferencia
}

\author{
Diego Alexander Vélez Quiroz
}

La Tienda de los milagros es a juicio de muchos, y comparto esa opinión, un monumento de inmenso valor para la cultura latinoamericana y, en particular, para la cultura brasileña. En esta novela Jorge Amado reúne de manera espontánea, y particularmente lírica, algunos de los aspectos más relevantes de la cultura, la política y la vida bahiana y, por extensión, de la brasileña.

La Tienda de los milagros fue publicada en un escenario político al cual no es ajena, 1969. Tampoco ha de olvidarse que Jorge Amado militó desde su juventud en el P.C.B. (Partido Comunista Brasileño); el vínculo con las ideas marxistas le permitió al escritor brasileño adoptar una posición crítica frente a los valores tradicionales de Occidente, de corte realista en la mayoría de sus novelas, sin embargo el realismo y la crítica son apenas algunos de los aspectos relevantes en la obra de Jorge Amado.

Aunque no se inscribe en la tradición que la crítica literaria ha llamado <<realismo〉>, la Tienda de los milagros no elude la realidad social y política de Bahía, por el contrario, da cuenta de problemáticas profundas que van desde el racismo y la discriminación hasta la desigualdad social y económica. La dosis de realismo se combina con la inclusión de elementos del candomblé afrobrasileño logrando, así, un perfecto equilibrio entre la realidad, dura y absoluta, y la imaginería mítica de los pueblos africanos. Un claro ejemplo de la forma cómo se combinan las realidades del pueblo bahiano con sus religiones y costumbres, es la descripción que el narrador realiza de la Tienda de los milagros, eje central de la novela de Amado:

Con la incisión de la madera, el tratamiento del milagro, los ayes causados por la tenaza, la venta de medicinas y la linterna mágica, maese Lídio Corró gana su sabroso y bien sudado dinerito. Pero en ese mismo local se deciden un montón de cosas. Allí nacen las ideas y maduran los proyectos que han de realizarse después en las calles, en las fiestas, en los terreiros. Allí discuten relevantes asuntos: la sucesión de Madres y Padres-de-santo, las cántigas de fundamento, la condición mágica de las hojas, las fórmulas de las brujerías y de los hechizos. Allí se fundan Ternos de Reyes, afoxéx de carnaval y escuelas de capoeira, allí se conciertan fiestas y conmemoraciones y se toman las medidas necesarias para garantizar el éxito del lavado de pies en la Iglesia del Buen Suceso y de las ofrendas de Mâe Dágua. La tienda de los milagros es una especie de senado que reúne a los notables de la pobreza, una asamblea numerosa y esencial. Allí se encuentran y dialogan iyalorixas, babalaôs, letristas, santeros, cantadores, marcadores de pasos, maestros de caopeira y maestros de artes y oficios cada uno con su mérito. (Amado, 1981, pág. 105).

Poligramas 39, primer semestre 2014, ISSN 0120-4130. 
Como es evidente, la novela recoge la riqueza popular de Bahía y revela el sincretismo y complejidad de una cultura que es, como muchos de los pueblos latinoamericanos, el producto del encuentro de varias cosmogonías.

Es difícil dar cuenta, en apenas unas páginas, de la compleja estructura de la novela y de la cantidad de voces y relatos que se tejen en su interior. Diré tan solo que dos son los relatos principales, intercalados, a través de los cuáles se desarrolla la novela y que son el medio por el cual surgen algunas historias breves y "maravillosas" cuya hondura debe ser motivo de un análisis más detallado.

El primero de los relatos es el de Fausto Pena. Como el clásico Fausto, el de Jorge Amado le vende su alma al diablo por alcanzar sus ambiciones. Durante la visita del premio Nobel norteamericano James D. Levenson, con motivo de algunas charlas que el Nobel ofrecería a propósito del "gran Pedro Archanjo", Fausto Pena ofrece a Levenson, de forma un tanto accidental, sus servicios como investigador y conocedor de la obra de Archanjo. Levenson accede a la solicitud bajo la condición de que la "novia" de Fausto, Ana Mercedes, le acompañé en un descubrimiento espontáneo de la cultura y el amor brasileños. La historia de Fausto es, en todo momento, el relato de su padecimiento ante las infidelidades de Ana Mercedes, la Margarita impoluta. Jorge Amado recurre a la obra de Goethe para elaborar un relato sencillo en el que se cruza la denuncia por la política corrompida, la manipulación de los medios de comunicación y el descuido de las expresiones populares del pueblo bahiano. Sin embargo, este relato le sirve de medio para detonar una historia mucho más profunda, la de Pedro Archanjo.

Pedro es el protagonista directo de ambos relatos, en el primero es el objeto de estudio, adulación y enriquecimiento de algunos; en el segundo es el gran Pedro Archanjo, Ojoubá, preferido de Xangó. Su historia es la historia de la cultura popular brasileña, del legado de África, de la fiesta, del sincretismo y del arduo trabajo por alcanzar la igualdad social y erradicar los dispositivos de exclusión que el pensamiento eurocéntrico implantó en las culturas del mundo. Pedro es apenas un asistente en la facultad de medicina, su condición de mestizo le impide ocupar un cargo más alto en la Universidad de Bahía; es también Ojoubá, los ojos de Xangó, guía y maestro de muchos en el Pelourinho; interesado por su cultura, Pedro se da a la tarea de recoger en notas aquellos aspectos que considera relevantes de su cultura y convertir las notas en un primer libro: La vida popular en Bahía.

Poligramas 39, primer semestre 2014, ISSN 0120-4130. 
Aplaudido por algunos y juzgado como inferior por otros, el libro de Archanjo hará carrera en la universidad y lo enfrentará, de forma discreta, a la humillación de un intelectual racista, de corte arianista, cuyo discurso supone la inferioridad de los negros y mestizos frente a la pureza de la piel blanca. La humillación, en la novela de Amado, será el detonante de una preocupación mucho más seria y arraigada de los discursos que validan el racismo y la exclusión como forma de organización social. Así, luego de la investigación, la abnegación y la experiencia de la vida, la novela culmina con un enfrentamiento entre los discursos racistas que circulan en la universidad de Bahía y la posición de Pedro Archanjo, posición que implica la aceptación y el respeto a la diferencia y, más interesante aún, el mestizaje como el factor distintivo de la cultura brasileña.

A lo largo de la historia se tejen muchos y variados que inciden en el desarrollo de la novela, aquí solo es posible resumir de manera muy escueta algunos de ellos, pero en el relato hay mucho más que el relato. Subyacen en la Tienda de los milagros algunos temas sobre los que me detendré brevemente.

8 Quiero, pues, que los hombres oren en todo lugar, levantando manos santas, sin ira ni contienda. 9 Asimismo, que las mujeres se atavíen de ropa decorosa, con pudor y modestia: no con peinado ostentoso, ni oro ni perlas ni vestidos costosos, 10 sino con buenas obras, como corresponde a mujeres que practican la piedad. 11 La mujer aprenda en silencio, con toda sujeción. 12 No permito a la mujer enseñar, ni ejercer dominio sobre el hombre, sino estar en silencio, 13 pues Adán fue formado primero, después Eva; 14 y Adán no fue engañado, sino que la mujer, siendo engañada, incurrió en transgresión. 15 Pero se salvará engendrando hijos, si permanece en fe, amor y santificación, con modestia. (1 $1^{\text {a }}$ Timoteo, 2: 8-15).

Esta visión machista de la mujer, unida a factores heredados de la cultura helénica que hicieron carrera en Europa y, luego, en el mundo, provocaron una negación sistemática del sentimiento del placer en la mujer y, como consecuencia, de su sexualidad en escenarios no reproductivos. Tal visión de mundo viajó desde Europa con los conquistadores, estos instauraron su dogma a sangre y fuego. Aún así, la presencia de pueblos nativos en el continente americano y la llegada de esclavos de diferentes puntos de África, influyeron profundamente en la cultura de los pueblos nacientes (antes sometidos y borrados). Así, la libertad (de culpa) que expresaban las mujeres venidas de África en relación con su cuerpo, la sexualidad abierta y pícara, y el respeto profundo por el otro, fueron elementos que se filtraron en la educación que los europeos instauraban en la América de la colonia. Pues bien, este trayecto de la restricción al placer produjo en una buena parte de las mujeres y los 
hombres latinos una nueva relación con el cuerpo, una forma de llevarse mucho más libre, una sexualidad sin culpa. Jorge Amado nos deja ver como el cuerpo es, entre las culturas, un factor distintivo de los latinoamericanos:

Fascinado, el sabio no quitaba los ojos de la moza, que avanzaba resueltamente hacia él, con el ombligo al aire. Nunca viera un caminar tan de danza, un cuerpo tan flexible, un rostro con tanta inocencia y malicia a la vez, blanca-negra-mulata. (Amado, 1981, pág. 27).

La cita corresponde a un comentario que el narrador hace a propósito de la reacción de Levenson, el "sabio norteamericano", al ver acercarse a Ana Mercedes, "blanca-negramulata". El fragmento no solo revela la extrañeza del americano (el extranjero) frente a la naturaleza del cuerpo latino, sino que además sugiere que el cuerpo y la sexualidad pueden, también, constituirse en escenarios de poder frente al dominador llegado de tierras extrañas (el extranjero). Esto último se hace evidente con la presencia de Fausto Pena quien, de forma lateral, adquiere su empleo de investigador gracias al deseo de Levenson por conquistar a Ana Mercedes.

Producto de la mezcla entre el infortunio y la castración de las mujeres en la cultura judíocristiana, el respeto que las culturas originarias de los pueblos americanos y los venidos de África profesaban por la mujer, y la ausencia de culpa como síntoma de la libertad en las culturas africanas, la belleza de la que habla Jorge Amado no es solo una belleza ornamental y licenciosa, es además un símbolo de la cultura latinoamericana, pueblos tempranos que evolucionan en el nuevo amanecer de Occidente, donde "La hermosura de las mujeres, de las simples mujeres del pueblo, es uno de los atributos de la ciudad mestiza, del amor entre las razas, de la clara mañana sin prejuicios”. (Amado, 1981: 32).

No termina allí el valor que Jorge Amado le otorga al cuerpo y a la sexualidad en la Tienda de los milagros, estos son además manifestaciones del vigor, de la potencia de los individuos, de la relación de los seres humanos con sus dioses, sus demonios y con su medio. Solo la sexualidad y el cuerpo le permiten al sujeto enfrentarse al poder de lo sobrenatural, el cuerpo y la sexualidad producen el equilibrio necesario entre el mundo de aquí y el de allá:

El gran embate duró tres días y tres noches sin el menor intervalo y fue la cumbre del regodeo: diez mil chingadas en una sola metida; tanto se calentó la iaba, en su furor infinito que, de repente, le dio un arrebato de encantamiento y se abrió en gozo, tal el cielo rompiéndose en aguacero. (Amado, 1981, pág. 141). 
Aún dirá más:

Se apoyaba en la verga como si ésta fuese su bastón de Obá, tanto había crecido en la impaciente espera; solamente con el olor a macho que despedía era capaz de desvirgar y preñar doncellas a una distancia de leguas. (Amado, 1981, pág. 139).

Una suerte de vitalismo surge de las palabras del narrador. Los fragmentos corresponden a un pasaje en el que Pedro Archanjo se ve enfrentado a la "mala intención" de una iaba, ser sobrenatural, femenino, que pretende acabar con la virilidad de Pedro y, de esta forma, humillarlo. Sin embargo, Xangó interviene y le otorga a Pedro los dones y secretos necesarios para combatir a la iaba. Esta complicidad entre hombres y deidades, en relación con los eventos que en muchas otras culturas serían mundanos, indica el respeto y la potencia que las culturas africanas y afroamericanas le otorgan al cuerpo y a la sexualidad.

La Tienda de los milagros es, además, una celebración de la vida. La novela revela el sentido de comunión permanente en el que se encuentran los hombres de la naciente (y al mismo tiempo ancestral) cultura y el vitalismo con el que se enfrentan a la realidad. La comunión permanente deviene en un sentido profundo de solidaridad que se hace mucho más evidente en las relaciones afectivas tales como la amistad y el amor. Tadeu, el hijo de la iaba (que será humanizada y mitificada en Rosa de Oxalá), luego del esfuerzo mancomunado de la comunidad que se reúne en la tienda de los milagros, obtiene su grado de doctor en ingeniería, este logro será, como todo, motivo de celebración de la vida y de la unión entre la comunidad refractada por Jorge Amado. Así, la celebración del grado del joven Tadeu es, como se verá, un ritual cuyas raíces están ancladas en el candomblé afrobrasileño:

Es una danza que viene de los comienzos del mundo: es el miedo, lo desconocido, el peligro, el combate, el triunfo, la intimidad de los dioses. Una danza de encantamiento y de coraje, del hombre contra las fuerzas ignotas, luchando y venciendo. Esa era la danza que la madre Majé Bassan dedicaba a Tadeu, en la Tienda de los Milagros. Era una abuela postiza danzando para el nieto doctor, recibido de ingeniero. (Amado, 1981, pág. 207).

La danza es la danza durante la celebración de la graduación de Tadeu, en ella no solo participan sus familiares, sino también sus amigos y todos aquellos de su comunidad que comulgan con sus semejantes. Además del arraigado sentimiento de otredad, hay una suerte de igualdad entre los individuos, de acuerdo a lo que nos muestra Jorge Amado, que no genera exclusión por motivos de género, raza, edad, religión, o cualquier otro tipo de característica distintiva. Por el contrario, la abuela mestiza y la abuela blanca bailan, cada 
una su danza, en un mismo ritual. El padre-de-santo y la madre-de-santo ocupan, igualmente, un papel fundamental en el terreiro y merecen un respeto igual. La doble participación matriarcal y patriarcal, hombre y mujer, madre-de-santo y padre-de-santo, suponen la cópula en lugar de la secta, la unión de los contrarios en lugar de su separación. La inclusión como principio no es exclusivo de los rituales, la Tienda de los milagros indica que surge de las entrañas del culto religioso y de su filosofía. Jorge Amado nos recuerda que la religión católica mutó en algunos de los países del Caribe y América, en los cuáles fue implantada. En países como Brasil, Haití y Cuba, por mencionar algunos, la religión católica fue asimilada y mezclada con los cultos de los pueblos originarios de estas zonas y de los esclavos venidos de África. El sincretismo es, también, manifestación de la inclusión como principio de convivencia:

"Sin embargo, ¿qué extraño parentesco unía estas imágenes tan íntimamente a los orixás del maestro Agnaldo? Entre estos elegidos del Vaticano y aquellos indígenas y mestizos del terreiro, había un rasgo común: la mezcla de sangres”. (Amado, 1981, pág. 18).

El sincretismo, así visto, es el producto de la criollización (del mestizaje), esta cambia la composición cultural establecida, requiere del reconocimiento equitativo de los diferentes elementos que la componen, sea cual sea su procedencia. Da una nueva orientación a la antigua concepción que limitaba la identidad cultural al origen y, por tanto, a la exclusividad y validación de expresiones particulares. En este caso debe aceptarse la pluralidad y la construcción en lugar de la procedencia. Este proceso, sin embargo, no es fácil, requiere tiempo, pues las culturas tienden a oponer resistencia a la mutación de sus culturas originales. Esta es, sin duda, una de las formas más positivas del reconocimiento de la valía de las culturas originarias de América y Africa, frente al canon de las culturas europeas que, de igual modo, reciben el valor que corresponde. En su Introducción a la poética de lo diverso (2002), Edouard Glissant ofrece una reflexión al respecto:

Los fenómenos de criollización son fenómenos importantes porque permiten practicar un nuevo abordaje de la dimensión espiritual de las humanidades. Un abordaje que pasa por una recomposición del paisaje mental de esas humanidades presentes hoy en el mundo. Porque la criollización supone que: los elementos culturales colocados en presencia unos de los otros deban ser obligatoriamente "equivalentes en valor", para que esa criollización realmente se efectué. 
El mestizaje es sin duda el eje central de la novela de Jorge Amado, los relatos y discursos que circulan a su interior están, todos, dirigidos a la reflexión en torno al tema del racismo y el mestizaje como factor identitario del pueblo bahiano. El mestizo es visto en relación, no en oposición, con el negro, el indio y el blanco, símbolo de la convivencia de las culturas encuentra rastros de su origen en diferentes expresiones culturales que la historia se ha empeñado en oponer. El mestizaje, en la Tienda de los milagros, no es solo una condición, es además una responsabilidad con los otros y con todo aquello que hace parte de la realidad de los individuos:

Soy un mestizo, tengo de negro y tengo de blanco, soy blanco y negro al mismo tiempo. Nací en el seno del Candomblé, me crié con los orixás y siendo todavía un mocito asumí un alto cargo en el Terreiro. Tengo un compromiso, una responsabilidad. (Amado, 1981: 271).

Somos de buena cepa, nuestra sangre mezclada es buena para la lucha, nunca retrocedemos ni renunciamos a nuestros derechos: vivimos para ejercerlos. (Amado, 1981, pág. 211).

En ambos fragmentos, además de la importancia que se le otorga al "ser mestizo", hay una particularidad: el mestizo, el negro y el indio (hablo de la totalidad del relato) hacen conciencia de su condición, entienden que hay rasgos distintos que, desde ciertas perspectivas de carácter incluyente, no deberían generar diferencias. Por ello, en este caso, el mestizo se enuncia y, a través de dicha enunciación, le arrebata a Europa la exclusividad de instaurar su visión del mundo, pues, como bien lo afirma Glissant, Europa ha marginado el resto del mundo, haciendo que ella sea el único lugar de la enunciación, mientras que las otras civilizaciones sean el lugar enunciado. (Fonseca, 2005:74).

Lo enunciado es objeto, no expresa un punto de vista y no se le asigna un lugar en la realidad, solo existe en la medida en que el enunciador le reconoce, dicho reconocimiento, no está de más decirlo, se mueve en dos dimensiones, el reconocimiento positivo o el negativo. El reconocimiento positivo implica la aceptación de lo enunciado como un valor concordante al del enunciador; el negativo, al contrario, implica el desconocimiento de las virtudes en lo enunciado y, por tanto, la anulación de su participación en el lugar del enunciador. A diferencia de lo que puede pensarse, en ambos casos hay exclusión, lo enunciado es visto como "objeto" pasivo y su valor dependerá siempre del que le asigne el enunciador. No se le reconoce como sujeto activo y plural en tanto no se ubica en el centro hegemónico del poder, su destino es el sometimiento al enunciador. La particularidad de la 
Tienda de los milagros, sin embargo, radica en la capacidad del autor de producir enunciación desde los diferentes tópicos de la cultura brasileña.

Así vistos, estos son tan solo algunos aspectos de la novela de Jorge Amado (y de su narrativa) que merecen una reflexión mucho más detenida. Hay que destacar, cómo no, el mensaje (extraído en la recepción y espontáneo en la elaboración) de tolerancia, la incitación a la pacífica convivencia con "lo diferente" que subyace en el mundo bahiano (Losada, 2003:12). La novela, aquí, es vista como un modelo de reflexión antropológica que permite restablecer el valor que es propio de las culturas sometidas en la dinámica de las sociedades a través de la historia.

\section{Bibliografía}

Amado, J. (1981). La tienda de los milagros. Madrid: Alianza Editorial / Editorial Losada.

Fonseca, P. M. (2005). Algunas reflexiones sobre la poética de la relación de Édouard Glissant. Contextos, 9(11), 71-84.

Glissant, E. (2002). Introducción a una poética de lo diverso. Barcelona: Ediciones del Bronce.

Losada, B. (2003). Jorge Amado y Bahía. Cuadernos Hispanoamericanos, 633, 7-12. 